\title{
ROBERT NOZICK E SUA TEORIA POLÍTICA: SERIA UMA ABORDAGEM RAZOÁVEL PARA A SOCIEDADE CONTEMPORÂNEA?
}

\author{
José Eduardo Ribeiro Balera $^{1}$ \\ Universidade Estadual de Londrina (UEL) \\ iD https://orcid.org/0000-0002-9534-4716
}

\begin{abstract}
RESUMO:
Para Robert Nozick, é preciso entender se o Estado é necessário e o modo como ele pode ser compreendido sem ofender direitos (como o direito natural de não coerção). O presente trabalho tem por objetivo explorar conceitos elementares da teoria de Robert Nozick para a conformação de uma teoria política razoável. Inicialmente, foi apresentado um panorama da concepção libertária desenvolvida por Nozick, baseado na primeira parte da obra Anarquia, Estado e Utopia (1974), tendo em vista que é um autor de bases teóricas distintas e pouco estudado pela academia. Posteriormente, foram analisados alguns aspectos de sua ideia de sociedade política e de seus integrantes, confrontando com conceitos teóricos do pensador contemporâneo John Rawls. Por fim, algumas características de tese de Nozick foram examinados para entender se seria uma doutrina abrangente e como poderia ser caracterizada como racional e razoável frente a pluralidade de concepções da boa vida
\end{abstract}

PALAVRAS-CHAVE: Estado mínimo; Libertarianismo; Concepção política de justiça.

\section{NOZICK AND HIS POLITICAL THEORY: IT WOULD BE A REASONABLE APPROACH TO CONTEMPORARY SOCIETY?}

\begin{abstract}
:
For Robert Nozick, one must understand that the state is needed and how it can be understood without offending rights (the natural right not coercion). This study aims to explore basic concepts of the theory of Robert Nozick and check if a reasonable political theory. Initially, it was exposed an

\footnotetext{
${ }^{1}$ Metrando em Filosofia pela Universidade Estadual de Londrina (UEL), Paraná - Brasil
} E-mail: J.ribeirobalera@ hotmail.com.
\end{abstract}


overview of the libertarian conception developed by Nozick, based on the first part of Anarchy, State, and Utopia (1974), because his thinking has been little studied and disseminated. Later, the idea of political society and its members were analyzed and compared with theoretical concepts developed by the contemporary philosopher John Rawls. Finally, some characteristics of Nozick's thesis were examined to understand if it would be a comprehensive doctrine and how it could be characterized as rational and reasonable on the plurality of conceptions of the good life.

KEYWORDS: Minimal state; Libertarianism; Political conception of justice

\section{Introdução}

O pensamento de Robert Nozick (1938-2002) incontestavelmente influenciou e ainda instiga a inúmeras reflexões na seara da filosofia política contemporânea. Apesar de sua obra, de marcas libertárias ${ }^{2}$, não ter sido amplamente divulgada, se comparada com outros autores do liberalismo como John Rawls e Ronald Dworkin, certamente sua relevância é tão notável e de essencial contribuição para a revisão crítica de "verdades", por exemplo, do surgimento natural do Estado e da inevitável interferência estatal na vida dos indivíduos.

O presente trabalho tem por objetivo compreender os elementos basilares da teoria de Robert Nozick, apresentados na primeira parte da obra Anarquia, Estado e Utopia (1974), bem como a sua potencialidade e colaboração na construção de uma teoria política centrada no indivíduo e na valorização da liberdade frente ao contexto politico hodierno.

Inicialmente, são explicitados conceitos fundamentais da teoria nozickiana, como de estado de natureza, estado ultramínimo e mínimo, além da explicação advinda da ideia de mão invisível e suas respectivas consequências. Neste âmbito é possível identificar às qualidades dos direitos adotados por Nozick e apresentar os alicerces em sua defesa.

Por conseguinte, são analisadas as concepções de sociedade política e seus integrantes contidos na obra nozickiana, confrontando-as as reflexões do pensador John Rawls, com o estabelecimento de aproximações e distanciamentos para melhor percepção do ideal de distribuição de justiça presente em cada um dos modelos propostos. Não se adentrará ao debate específico ocorrido entre Nozick-Rawls, uma vez que se trataria de um exame particularizado do substrato das teorias das justiças de cada um dos referidos autores e extrapolaria o objeto delineado para o presente artigo. A proposta aqui apresentada concentra-se nos conceitos redimensionados por John Rawls na obra Liberalismo Político (1993), sendo que as críticas de

${ }^{2} \mathrm{O}$ libertarianismo é considerado um liberalismo mais extremado ou conservador.

Robert Nozick e sua teoria política: seria uma abordagem razoável para a sociedade contemporânea? - José Eduardo Ribeiro Balera 
Nozick foram especialmente direcionadas ao projeto inicial rawlsiano explicitado no livro Uma Teoria da Justiça, de 1971 (mesmo que não se verifique uma ruptura substancial entre ambas as obras de John Rawls).

Por fim, a partir de noções fundamentais do pensamento rawlsiano, são exploradas possíveis hipóteses como (i) a caracterização do pensamento de Nozick enquanto uma doutrina abrangente, sua latência para uma concepção política de justiça e (ii) a presença das qualidades do racional e do razoável em sua caracterização, haja vista à problemática das divergências políticas na sociedade contemporânea que é marcada pelo pluralismo de concepções de vida boa.

\section{O libertarianismo de Robert Nozick: elementos basilares de sua teoria}

Robert Nozick, filósofo e professor norte-americano da Universidade de Harvard, tem como obra de maior destaque o livro intitulado Anarquia, Estado e Utopia (1974), no âmbito da teoria moral e política, apesar de também ter elaborado trabalhos acerca de outras temáticas, por exemplo, na seara da epistemologia. Contemporâneo de John Rawls, Nozick possui um viés político totalmente distinto, assinalado pelos traços do individualismo. Declarou que seu anseio inicial fosse resistir às críticas libertárias, porém acabou sendo conquistado por elas. Em suas palavras iniciais:

\footnotetext{
Percebi, com relutância, que, em razão de várias reflexões e argumentações, estava me deixando convencer pelas teorias libertárias (como são muitas vezes chamadas atualmente). Este livro não contém muitos indícios de minha relutância anterior. $[\ldots]$

Minha relutância anterior não está presente neste livro porque deixou de existir. Acostumei-me, ao longo do tempo, com essas ideias e com suas consequências, e agora vejo a política através delas. (Nozick, 2011, p. X).
}

Para esta obra, que se concentra inicialmente e em grande proporção na exploração de argumentos acerca da real essencialidade da invenção da figura do Estado, nada mais adequado do que partir suas investigações da ideia do "estado de natureza". Este instrumento foi o definido por Nozick para compreender o modo em que o Estado deveria vir a ser organizado e se sua existência seria adequada diante dos direitos pertencentes aos indivíduos. Ou seja, o pensador defronta-se com a indagação "Por que não ficarmos com a anarquia?" (NOZICK, 2011, p. 3).

O estado de natureza resgatado por Nozick, aos moldes do elaborado por John Locke, pressupõe a existência do direito natural do qual cada indivíduo é livre para determinar suas ações e dispor de seus bens, dentro dos limites das próprias leis de natureza, ou seja, sem infringir ou prejudicar os direitos uns dos outros (NOZICK, 2011, p. 10-12). No entanto, não seria possível negar o surgimento de disputadas, reclamações e a própria ideia de 
vingança. A existência de "inconveniências do estado de natureza", como a insuficiência dos indivíduos na garantia de seus direitos e a inexistência de um indivíduo imparcial (árbitro) para a resolução das contendas e disputadas entre sujeitos, pois estes certamente seriam parciais enquanto juízes das próprias causas, exigiria uma proposta para solucionar tais problemas. Para Locke, o remédio seria o governo civil, enquanto Nozick arquiteta uma resposta alternativa e racionalmente coerente.

Direcionados pela "mão invisível”, os indivíduos seriam levados, por conveniência, a formação de associações de proteção mútua, pois a união garantiria força na tutela e imposição dos seus direitos. Porém, alguns inconvenientes manter-se-iam, como o ônus para que todos se mantivessem a disponibilidade uns dos outros para proteção, além dos riscos em se ficar à disposição de indivíduos paranóicos e briguentos que poderiam utilizar o argumento da legítima defesa ao grau de ferir direitos de outros se utilizando da associação. Por não ser tão vantajosa, haveria a possibilidade de se estabelecer agências especializadas para esta atividade de proteção privada (NOZICK, 2011, p. 14-18). Seria tendente que os indivíduos viessem a aderir à agência mais forte.

Neste cenário, tratando-se de um mercado específico, uma vez que a atividade de proteção é peculiar e de maior exigência à garantia de efetividade, existiriam três hipóteses que conduziriam ao monopólio de fato: (i) os clientes das agências mais fracas passariam a migrar para a agência mais forte e que viesse a se impor e vencer na hipótese de conflitos; ( ii) existindo agências que seriam mais fortes em determinada localidade, por exemplo, onde se encontram sua sede, o monopólio de fato poderia ser definido pela territorialidade; iii) mesmo com a pluralidade de agências, cada uma em determinada região, poderia vir a existir conflitos entre elas, tornando-se necessário a instituição de um tribunal e a definição de regras de jurisdição, para resolução das divergências, caso contrário, às agências se enfraqueceriam.

Naturalmente, a agência dominante se manteria e as agências mais fracas iriam desaparecer do mercado de proteção, pois existiria naturalmente um violento conflito entre si, além da tradicional disputa por clientes que almejam a proteção (NOZICK, 2011, p. 20). Esta agência protetora dominante é denominada de Estado Ultramínimo, monopoliza o uso legítimo da força de fato e não de direito e fornece o serviço de proteção tão somente aos indivíduos que pagam por sua tutela. (NOZICK, 2011, p. 32). Todavia, ainda restariam circunstâncias a serem resolvidas, por exemplo, diante da imprecisão de eventuais disputas que surgiriam entre independentes e clientes da agência dominante. Neste momento, por uma obrigação moral, torna-se essencial a passagem do Estado Ultramínimo para o Estado Mínimo e os serviços de proteção passam a ser prestados também aos independentes, enquanto consequência compensatória da atuação impositiva estatal da proibição de qualquer aplicação própria da justiça por 
parte dos independentes, inclusive, para garantir maior eficiência dos serviços prestados - expressão do princípio da compensação desenvolvido por Nozick.

Em seu aspecto mais genérico, "o princípio da compensação exige que as pessoas sejam compensadas por serem impedidas de praticar determinadas atividades de risco", como a aplicação dos próprios procedimentos de justiça (NOZICK, 2011, p. 105). No caso do Estado Mínimo, proíbe-se que os independentes venham a aplicar sua punição aos clientes que possam ter, em hipótese, violado seus direitos, em decorrência do princípio da compensação, "as pessoas que decretassem essa proibição e dela se beneficiassem teriam de compensar os que se vissem em posição desvantajosa devido a esse procedimento" (NOZICK, 2011, p. 141). Cumpre lembrar que o Estado nozickiano pode ter tão somente os direitos que as pessoas individualmente também poderiam ter (como de proibir a aplicação de procedimentos de justiça não confiáveis), mas não poderia ser titular de direitos especiais, como os exercidos por modelo de Estado weberiano, pois o Estado nada mais é que uma agência dominante que exerce as atividades de proteção em nome de seus clientes e oferece seus serviços aos independentes, como medida compensatória e viabilizadora da efetividade de sua atuação.

A defesa de Robert Nozick para legitimar um Estado Mínimo é diferenciada, pois ele acredita ter justificado sua criação e sua necessidade moral sem comprometa ou violar os direitos individuais, porém seu conceito de estado não compartilha características que comumente são atribuídas ao Estado Tradicional, ao molde weberiano (marcado pelo monopólio de direito do uso da força).

A teoria nozickiana tem natureza deontológica, aspecto que o aproxima do pensamento de John Rawls, uma vez que ambos partem em defesa da existência de direitos básicos que não possam ser violados, inclusive, inadmitindo que os direitos de determinados indivíduos sejam sacrificados ou deturpados em prol do bem-estar de outros, uma alternativa aceita pela linha utilitarista. Além disto, ambos os autores compartilham uma influência do pensamento kantiano, especialmente, por defenderem que os indivíduos não podem ser tratados e utilizados meramente como meios, mas devem ser reconhecidos como um fim em si mesmo (GARGARELLA, 2008, p. 35).

O escritor argentino Roberto Gargarella (2008, p. 35-36) identifica três características elementares dos direitos admitidos e expressos na teoria de Nozick. Sucintamente, tais direitos naturais: (i) são tão somente negativos: significa a tutela do direito de não interferência, pois indivíduo não pode ser coagido ou forçado caso não deseje algo, o que levaria a uma rejeição dos direitos positivos. Para Gargarella, os direitos positivos só se resultariam de "transações voluntárias entre as pessoas". (ii) Atuam como restrições laterais às ações dos outros: trata os direitos enquanto uma esfera 
que não pode ser inviolada frente às pretensões dos demais indivíduos, ou seja, é o limite à liberdade; (iii) são exaustivos: tem prevalência frente a qualquer outra consideração ou pretensão moral que venha a surgir, por exemplo, não haveria possibilidade de se conceder uma prioridade moral a outro direito, como a preservação ambiental em detrimento ao direito de propriedade, pois este já é reconhecido e não pode ser violado ou sofrer qualquer interferência.

Porém, para o autor argentino, parece discutível se estes direitos negativos são os únicos que devam ser considerados no momento em que se pretende sustentar uma concepção teórica que se dispõe a propiciar uma conjuntura coerente para uma vida relevante. Nesta crítica, o escritor salienta:

Por que não afirmar, de modo razoável, que para que cada um possa planejar sua vida é necessário também que o Estado garanta certos benefícios básicos de previdência social? Nozick poderá dizer-nos, diante dessa queixa, que, se começarmos a tornar exigíveis certos direitos positivos, colocamos em sério risco a possibilidade de que cada um molde, a seu critério, sua própria vida: sempre se poderia exigir de nós algum sacrifício adicional, em prol de melhorar as condições de algum outro. (GARGARELLA, 2008, p. 36-37).

Neste aspecto, a resistência de Robert Nozick parece fazer maior sentido, uma vez que o ônus fixado por um Estado de bem-estar social poderia representar um constante sacrifício individual. Todavia, não pode ser desconsiderado que a abstenção da atuação estatal em tais compromissos inviabilizaria as circunstâncias e condições que os indivíduos necessitam a real autopropriedade de suas vidas, diante da ausência de uma estrutura básica para sua condução autônoma. Para Nozick, esta leitura final não teria pertinência, haja vista que a condição básica é a não interferência e não haveria qualquer obrigação moral de se garantir um substrato aos indivíduos para que atinjam todos ou grande parte de seus objetivos, sob o simples argumento de impedi-los de viver a frustração.

Logo, a garantia da não interferência ou proteção é o papel principal de seu Estado Mínimo, não existindo relevância a manutenção de uma conjuntura favorável aos sujeitos para que prossigam com os planos projetados/esperados e suas expectativas de vida. A saúde, a educação e tantas outras prestações, que são tratados por muitos autores como direitos, são bens na teoria nozickiana como a segurança e os sistemas de proteção, de maneira que podem ser ofertados e adquiridos livremente no mercado. As diferenças entre os indivíduos são ignoradas por Nozick, pois o direito natural pertencente a todos é a liberdade, em seu sentido negativo. Neste aspecto há um sensível distanciamento comparado com outros autores, por exemplo, John Rawls. Para Rawls, uma concepção política de justiça deve buscar a garantia da liberdade, o acesso às oportunidades, sem que se torne 
uma teoria igualitarista, posto que as desigualdades são justificadas e permitem o constante incremento e desenvolvimento da dinâmica social ${ }^{3}$. Porém, os talentos, por exemplo, são tratados na teoria rawlsiana como parte de um acervo comum, assim como a cultura, sendo admissível que sejam utilizados em prol dos menos talentosos. Como expressão do princípio da diferença, John Rawls defende:

El principio de diferencia representa, en efecto, el acuerdo de considerar la distribución de talentos naturales, en ciertos aspectos, como un acervo común, y de participar en los beneficios de esta distribución, cualesquiera que sean. Aquellos que han sido favorecidos por la naturaleza, quienesquiera que sean, pueden obtener provecho de su buena suerte sólo en la medida en que mejoren la situación de los no favorecidos. Los favorecidos por la naturaleza no podrán obtener ganancia por el mero hecho de estar más dotados, sino solamente para cubrir los costos de su entrenamiento y educación y para usar sus dones de manera que también ayuden a los menos afortunados. (RAWLS, 1995, p. 104)

A interferência, que representa um ato de violência aos libertários, é tida por Rawls como parte da concretização da justiça. Talvez este seja um dos motivos que marcaram as críticas entre os dois pensadores norteamericanos. Talvez Nozick não recuse a ideia de igualdade, uma vez que determinada comunidade poderia instituir um acordo de que toda produção econômica das famílias fosse dividida igualmente, condicionado ao fato de que todos venham a consentir expressamente neste acordo. Sua posição se demonstra resistente e contrária ao estabelecimento de normas que venham a impor critérios e procedimentos em prol da igualdade, sendo inadmissível o argumento de que todos consentiram implicitamente.

Porém, também surgiria outra incerteza sobre a existência tão somente de direitos negativos, pois o Estado Mínimo atuaria na tutela dos indivíduos que colaboram com suas atividades, ou seja, dos seus clientes,

\footnotetext{
${ }^{3}$ A concepção política de justiça formulada por Rawls foi denominada de justiça como equidade. De modo sucinto, o autor traça os seguintes princípios: "a. Cada pessoa tem um direito natural a um sistema plenamente adequado de direitos e liberdades iguais, sistema esse que deve ser compatível com um sistema similar para todos. E, neste sistema, as liberdades políticas, e somente estas liberdades, devem ter seu valor equitativo garantido. B. As desigualdades sociais e econômicas devem satisfazer duas exigências: em primeiro lugar, devem estar vinculadas a posição e cargos abertos a todos em condições de igualdade equitativa de oportunidades; em segundo lugar, devem se estabelecer para benefício possível dos membros menos privilegiados da sociedade" (RAWLS, 2011, p. 6).O direito de liberdade considera por Rawls é positiva, distinguindo-se das pretensões da teoria nozickiana. Rawls estabelece um pensamento que visa compatibilizar a igualdade e liberdade dos cidadãos e não de clientes.

${ }^{4}$ A versão original em inglês se encontra na página 87. Cf. RAWLS, John. A theory of justice. Ed. Rev. Massachusetts: Harvard University Press, 1999.
} 
impedindo em determinado território que se utilize a autotutela/autodefesa e, em compensação, asseguraria também aos independentes o benefício de proteção e de aplicação de procedimentos confiáveis para justiça e resolução de conflitos. Não seria este um direito positivo? Quem arcaria com os custos da proteção e dos serviços prestados aos independentes? Para esta última pergunta certamente seriam os clientes que financiam as atividades para sua proteção e de certo modo estariam sendo expropriados de maior maneira para garantir um serviço de proteção aos independentes. Seria mais racional que se mantivessem como clientes ou abandonassem a contribuição voluntária do serviço de proteção?

Logicamente que Nozick não cede a tal contradição, pois aqueles que poderiam pagar pelos procedimentos adequados não restariam prejudicados a ponto de serem compensados. Enquanto efetivação do princípio da compensação, os proibidores só deveriam compensar as desvantagens decorrentes da proibição de que os independentes venham ameaçar de punir aqueles clientes da agência dominante, sendo subtraída uma quantia que represente os custos que não seriam ocasionados pela parte proibida caso não viesse a sofrer a proibição. (NOZICK, 2011, p.142). Nozick justiça o motivo de proteção de não clientes:

[O Estado] tem a obrigação moral de fazer isso em virtude do princípio da compensação, que exige que os que agem em causa própria para proteger, a fim de aumentar a própria segurança, compensem aqueles aos quais proíbem de praticar ações perigosas que possam, na verdade, mostrar-se inócuas em razão das desvantagens eles causadas. (NOZICK, 2011, p. 146).

As dificuldades de Nozick em sustentar esta posição decorrem do fato de existir um suposto direito positivo dos não clientes, uma vez que se constituiria uma obrigação moral do Estado em tutelá-los. Outra controvérsia que surge é na hipótese dos independentes não desejarem ser tutelados, pois a prestação de tal serviço de proteção contra suas vontades certamente figura uma ofensa e uma interferência direta à liberdade.

Tais questionamentos evidenciam possíveis fragilidades no direcionamento do pensamento de Nozick, de maneira que o Estado Mínimo, por ele sustentado, parece expandir-se de tal modo a ferir indiretamente o princípio basilar de não interferência e até mesmo a propriedade individual.

\section{Entre Nozick e Rawls: aportes acerca da sociedade política e de seus integrantes}

Em sua teoria moral e política, Nozick não estabelece um esquema político ou social que seja definido como sociedade, diferentemente da teoria rawlsiana, visto que Nozick entende que toda sua análise parte do 
estado de natureza e se dirige ao Estado Mínimo por explicações da mão invisível. Logo, ninguém está obrigado a corroborar determinada conformação, inclusive, sendo admitida a manutenção de não clientes ou os denominados independentes, mesmo que exista o monopólio de fato do uso da força, motivo pelo qual inicia sua obra com as questões: "Se o Estado não existisse, seria necessário inventá-lo? Precisaríamos de um Estado, e teria ele de ser inventado?" (NOZICK, 2011, p. 3).

Em outros termos, sua concepção de sociedade é mais aberta que de outros teóricos políticos, diante da menor rigidez e imposições, desde que respeitados os limites naturais da liberdade negativa e do direito de propriedade (com sua teoria da titularidade). A ideia de sociedade será apresentada com maios detalhes no decorrer do presente artigo, comparando-se com alguns aspectos basilares do pensamento de John Rawls.

O estado mínimo nozickiano teria funções limitadas e estritas à manutenção da segurança e aplicação de procedimentos confiáveis, caso contrário, violaria o direito dos indivíduos na hipótese de ampliação de suas funções, ofendendo diretamente seu dever de não interferência. Logo, não há que se falar em assistência médica pública, previdência, assistência social, educação pública ou outras iniciativas sustentadas pela tributação, pois a ordem existente é regida pela livre transferência voluntária. Neste sentido, há um distanciamento de outros teóricos liberais, por exemplo, a sociedade da teoria rawlsiana é vista como um sistema equitativo de cooperação.

Rawls entende que a relação política se diferencia por traços específicos, dentre os quais se destacam na ordem constitucional: (a) é uma relação que se desenvolve pelos indivíduos inseridos em uma determinada estrutura básica da sociedade, que se ingressa com o nascimento e deixa-se com a morte, independente do voluntarismo ou das relações de afetividade ${ }^{5}$; (b) o poder político embasa-se no poder coercitivo utilizado pelo Estado, via a aplicação de sanções, com a autoridade do uso da força para a imposição de suas disposições legais, por isso, em último grau, o poder político é um poder público de um corpo coletivo constituído por cidadãos livres e iguais (RAWLS, 2000a, p. 181-182). Este último atributo implica diretamente no princípio liberal de legitimidade ${ }^{6}$ rawlsiana, no qual as deliberações não se reduzem a um jogo de barganha política e cuja exigência é "a coerência do

\footnotetext{
${ }^{5}$ Diferentemente da esfera pessoal e familiar, pelo seu contorno afetivo, e das associações integrantes da sociedade civil, pela voluntariedade, a sociedade política é fechada e orientada por outros padrões, objeto de pesquisa de Rawls.

${ }^{6}$ Ressalta-se que para Dworkin o governo legítimo deve demonstrar igual preocupação pela destinação sobre os cidadãos que tem sobre seu domínio, como também respeitar a responsabilidade e o direito dos indivíduos quanto ao que pretendam fazer com a vida que consideram de valor. Definindo-se os princípios do igual cuidado (equal concern) e da responsabilidade especial (special responsibility). Cf. DWORKIN, Ronald. Justice for Hedgehogs. Massachusetts: Harvard University Press, 2011.
} 
poder político com a constituição, cujos elementos possam ser endossados por cidadãos livres e iguais a partir de princípios e ideais aceitáveis para a razão humana comum" (SILVEIRA, 2007, p.15).

Por sua vez, o pensamento de Nozick (2011, p. 23) se justifica com um direcionamento próprio a partir da figura da mão invisível, não pretendendo levar em consideração conceitos próprios e constitutivos dos fenômenos que se pretende explicar, em suas palavras:

[...] ao contrário das explicações indiretas, elas não explicam os modelos complicados por meio da inclusão dos conceitos de modelos maduros como objetos dos desejos ou crenças das pessoas. Assim, as explicações dos fenômenos pela mão invisível oferecem uma compreensão mais ampla do que as explicações que os apresentam como resultado de um projeto intencional, como o objeto mesmo das intenções das pessoas. (NOZICK, 2011, p. 23).

Por esse motivo, a ideia de cidadão não se apresenta no pensamento de Nozick, pois ele não pretende estabelecer um conceito político de pessoa $^{7}$, diferentemente de Rawls, que venha a ser participante público. A orientação e o desenvolver de seu estudo tem como referência a lógica de mercado, em que a proteção é um bem oferecido e com certas particularidades. A figura do cidadão é substituída pela imagem do cliente que atua racionalmente.

No modelo construído por Nozick, a propriedade ganha um caráter forte, excluindo qualquer formato redistributivo. Para Kymlicka (2006, p. 123), a ideia de propriedade em Nozick seria uma decorrência intuitiva ou mesmo uma derivação da "posse de si mesmo", sendo assim, a distribuição justa seria sensível a ambição. ${ }^{8}$ Cumpre lembrar que a ideia de "posse de si mesmo" pode ser interpretada como um artifício do tratamento das pessoas como iguais.

Ao defender o direito natural de não interferência, ou seja, a liberdade em seu sentido negativo, seria lógico que todo o pensamento de Nozick estivesse fundada em uma vertente da teoria da liberdade. Porém, para Will Kymlicka (2006, p. 171), uma interpretação admissível entende que o pensamento nozickiano não é alicerçado em uma teoria da liberdade, pois a autopropriedade não é derivada da liberdade.

\footnotetext{
${ }^{7}$ Rawls estabelece uma concepção política de pessoa adequada ao conceito de democracia constitucional bem-ordenada, estando minuciosamente detalhada no $\S 5^{\circ}$ da conferência I Ideias fundamentais, constante na obra Liberalismo Político (1993).

${ }^{8}$ Para Kymlicka (2006, p. 123), esta seria mais uma diferença com o pensamento de liberais como Dworkin e Rawls, pois além de sensível a ambição, a distribuição justa deverá ser insensível à dotação, pois “é injusto que os naturalmente desfavorecidos morram de fome simplesmente porque não têm nada a oferecer aos outros na troca livre, ou que crianças não tenham assistência médica ou educação apenas porque nasceram em uma família pobre".
} 
Essa posse de nós mesmos, porém, não é derivada de nenhum princípio de liberdade. Ele não diz que a liberdade vem primeiro e que, para sermos livres, precisamos da posse de nós mesmos. Ele não nos oferece nenhum ponto de apoio na ideia de liberdade como algo anterior à posse de si mesmo, a partir do qual possamos derivar a posse de nós mesmos. Sua visão é, antes, que a abrangência e a natureza da liberdade que devemos usufruir são uma função da nossa posse de nós mesmos (KYMLICKA, 2006, p. 171).

Por consequência, seu libertarianismo comunga, junto aos adeptos da ideia de igualdade liberal, o comprometimento ao princípio que almeja respeitar a livre escolha das pessoas e repudia a correção das desigualdades e suas circunstâncias. Em seu grau mais elevado, a impossibilidade de correção das circunstâncias desiguais pode arruinar seus valores mais fundamentais, como o valor da autodeterminação. Logo, "a negação libertária de que as diferenças imerecidas nas circunstâncias dão origem a direitos morais sugere um fracasso quase incompreensível em reconhecer as consequências profundas de tais diferenças". (KYMLICKA, 2006, p. 198).

Em alguma medida, ao consolidar a ideia de propriedade e o direito natural de não interferência, em respeito às escolhas das pessoas, Nozick define aspectos elementares da estrutura básica da sociedade $^{9}$ e com consequências em toda a dinâmica social e na "distribuição" da justiça.

Na proposta de Nozick, algumas situações podem aparentemente ser similares, porém são moralmente distintas. Roberto Gargarella (2008, p. 48) traz algumas hipóteses ${ }^{10}$ que ilustram tal afirmativa: (i) numa primeira construção hipotética, seria considerada reprovável moralmente a situação em que determinado indivíduo fosse obrigado a laborar beneficiando outro, estando sob a mira de uma arma; (ii) contrariamente, não haveria moralmente qualquer problema se um indivíduo desempregado viesse a celebrar um contrato de trabalho altamente desvantajoso para si (que na atualidade seria considerado exploratório) e em más condições, pois não terá sido violado seus direitos, nem mesmo sido forçado a tal escolha, mesmo que seja a única oportunidade existente no mercado e sua decisão tenha sido guiada pelo fato de seus familiares estarem definhando na miséria. Sob essa

9 A definição dos princípios de justiça que seriam aplicados na definição da estrutura básica da sociedade foi um dos objetos de investigação de maior preocupação para Rawls. A estrutura básica da sociedade pode ser entendida como o modo em que as principais instituições sociais se organizam em um único sistema, estabelecendo direitos e deveres fundamentais, bem como estruturando a distribuição de vantagens que resultam da cooperação social. Nas palavras do pensador norte-americano, "a constituição política, as formas de propriedade legalmente admitidas, a organização da economia e a natureza da família, todas, portanto, fazem parte dela" (RAWLS, 2000b, p. 3). Cf. RAWLS, John. Justiça e Democracia. Trad. Irene Trad. Irene A. Paternot. São Paulo: Martins Fontes, 2000 b.

${ }^{10}$ As hipóteses sofreram pequenos incrementos de ordem enfática. 
perspectiva, ele poderia aceitar ou recusar a proposta de emprego no livre exercício de seu direito. Logo, conduz a uma concepção de sociedade em que o sujeito é o responsável pelos pactos celebrados ou recusados a celebrar.

Esta construção é impactante se considerarmos, como ressalta Sérgio Morresi (2002, p. 287), que a teoria de Nozick defende, de certo modo, a concepção de que o ser humano é valioso e por este motivo sua vontade deve ser respeitada, entendendo-se o conceito de valioso como "aquilo que consegue conciliar a diversidade na totalidade, sem que, no entanto, cada um dos elementos seja descaracterizado". Deste modo, ao se ter um valor intrínseco, obtém seu sentido ao ser integrar e compor uma sociedade, que não poderá ser eliminado por meio de sua unidade, mas terá a oportunidade de incorporar "uma nova diversidade harmoniosa".

Enquanto "restrições morais indiretas", os direitos de um indivíduo determinam os limites e restrições das ações dos outros, reciprocamente, de modo que o valor de cada indivíduo não pode ser compreendido como restrição ao valor dos outros, já que não é comensurável, mas sim restrição à liberdade de agir. Resgatando os ensinamentos de Álvaro de Vita, as restrições morais indiretas expressam limitações caracterizadoras de "deveres", como não matar, não ofender a propriedade de outro, do que mais propriamente de "direitos" (MORRESI, 2002, p. 288).

\begin{abstract}
O problema aqui é que se aceitarmos (como parece fazer Nozick) que os indivíduos são seres sociais, deveríamos aceitar também que a liberdade não pode ser entendida só em termos negativos (como ele também parece supor). Se nossa realização como seres humanos está assentada na premissa de que devemos ser valorizados por nossa unidade formar parte de uma diversidade que não nos negue, o outro não é só limite à minha liberdade, mas também a condição de possibilidade da mesma. (MORRESI, 2002, p. 288).
\end{abstract}

Morresi (2002, p. 288) traz outro argumento importante na análise do pensamento nozickiano, pois considera que a liberdade e o uso discricionário da propriedade acabam por ser equiparados na teoria do pensador norte-americano. Se o conceito de liberdade está diretamente relacionado a não coerção, seria admissível estabelecer graus/medir a liberdade do indivíduo tendo como referência aquilo que ele é capaz de concretizar em consonância a própria vontade, sendo que a ideia de vontade parece ser distanciada do seio social e se torna um elemento meramente subjetivo. Assim, se o valor do ser humano e os bens que lhe pertença sejam reconhecidos como os limites morais à atuação dos outros indivíduos, poder-se-ia deduzir que uma pessoa é mais livre proporcionalmente quanto mais tenha sob sua posse, surgindo uma simples equação que entende que a distribuição de bens é também definidora da distribuição da própria liberdade. 
Desta conclusão decorreria uma consequência importante: se todo indivíduo merece sua liberdade, de alguma maneira Nozick deveria admitir a redistribuição de bens, ao menos no sentido rawlsiano, que viabilizasse o exercício da liberdade. Porém, como destaca André Assi Barreto (2014, p. 16):

Os direitos ocupam uma posição fundamental na teoria de Nozick e eles devem ser entendidos como restrições morais indiretas, e não como objetivos a serem alcançados. Tratar os direitos como objetivos significa dizer que eles podem ser sacrificados se for julgado que há outros objetivos mais importantes. Tratar os direitos como restrições morais, por outro lado, significa restringir a forma com que os objetivos humanos podem ser alcançados, de modo que essas não devem de forma alguma violar tais direitos. Para Nozick, teorias morais pautadas puramente por objetivos (e que não incluem restrições morais) são problemáticas por não respeitar a inviolabilidade das pessoas. É da própria natureza dessas teorias que haverá casos em que elas requererão que nós sacrifiquemos os direitos individuais para alcançar outros objetivos. Nos termos kantianos, tais teorias permitem o tratamento de pessoas como meros meios, e não como fins em si mesmas, o que Nozick considera inaceitável.

Neste sentido, há um sentido próprio e razoável em defesa do pensamento de Nozick, garantindo coerência e respeito ao indivíduo. Entretanto, saber em que medida as restrições morais indiretas são absolutas ou não passa a ser um problema a parte em prol da manutenção ou não de sua teoria. $\mathrm{O}$ estreito limiar em circunstâncias como o direito do feto à vida e da não interferência da mãe em contraposição à autopropriedade da gestante sob seu corpo no caso do aborto manifestam indícios deste conflito e também continuidade das divergências das diferentes concepções de vida de boa.

\section{Teoria moral, política e sociedade: seria o libertarianismo mais uma doutrina abrangente?}

Para Rawls (2011, p. 18), a sociedade na verdade deve ser entendida como um sistema de cooperação em termos equitativos. A ideia de cooperação não se confunde com mera atividade coordenada socialmente, mas orientada por normas e procedimentos que são reconhecidos publicamente. Talvez as ideias de liberdade negativa e de transferências voluntárias poderiam funcionar como componentes para uma concepção de cooperação social, caracterizando-se enquanto normas a serem, sem embargo, reconhecidas por todos.

Neste sentido, conquanto Nozick não objetivasse tal conclusão, por trás de sua teoria é possível identificar aspectos mínimos de uma cooperação 
social. O próprio Estado Mínimo, o princípio de compensação e a aplicação de procedimentos de justiça confiáveis aos independentes também demonstram uma potencial atividade cooperativa, mesmo que distante do projeto rawlsiano.

Porém, Rawls acredita que não basta ser uma atividade cooperativa definidora da sociedade, mas também enquanto um sistema equitativo, ou seja, "são termos que cada participante pode razoavelmente aceitar, desde que os demais aceitem" (RAWLS, 2011, p. 18), especificando-se a ideia de reciprocidade. Como defende o pensador:

[...] todos os que estão envolvidos na cooperação e que fazem sua parte, como as normas e os procedimentos exigem, devem beneficiar-se de uma forma apropriada, avaliando-se isso por padrão adequado de comparação. [...] Como objeto fundamental da justiça é a estrutura básica da sociedade, esses termos equitativos são expressos pelos princípios que especifiquem os direitos e deveres fundamentais no âmbito das principais instituições da sociedade e que regulam as disposições da justiça de fundo ao longo do tempo, de modo que os benefícios produzidos pelos esforços de todos sejam distribuídos equitativamente e compartilhados de uma geração às seguintes. (RAWLS, 2011, p. 19).

No que se referem aos termos equitativos da atividade cooperativa, os dois modelos filosóficos se distanciam sensivelmente, pois Nozick não reconhece tal condicionante. Para ele, a liberdade negativa (direito de não interferência) é um direito natural e inerente à própria garantia do homem enquanto um fim em si mesmo, fato que permitira a deduzir a dispensa de seu reconhecimento ou da reciprocidade para instituição da coordenação social.

Para Nozick (2011, p. 40):

[...] não existe nenhuma entidade social com um bem que passe por algum sacrifício para seu próprio bem. Só existem indivíduos, indivíduos diferentes, com suas próprias vidas individuais. Usar uma dessas pessoas para beneficiar as outras significa usá-las em benefício das demais.

Nesta medida, o pressuposto nozickiano e as consequências derivadas constituem-se, em última análise, enquanto partes de uma doutrina abrangente ${ }^{11}$, com traços próprios da racionalidade de influência kantiana, em defesa de uma verdade tida como inabalável e presumidamente compartilhada por todos como una. Esta seria uma das críticas apresentadas

\footnotetext{
${ }^{11}$ Para alguns, como Thomas Nagel, haveria uma ausência de fundamentos na doutrina constituída por Nozick. CF. NAGEL, Thomas. Nozick: Libertarianism without Foundations. In: Other Minds. Critical Essays 1969-1994. Oxford University Press, 1995, p. $137-149$.
} 
à obra Uma Teoria da Justiça de John Rawls ${ }^{12}$ e que parece ser aplicada a Robert Nozick.

Para melhor esclarecer, é importante recordar algumas reformulações e esclarecimentos trazidos por John Rawls na obra Liberalismo Político (1993), como de concepção política de justiça e concepções morais abrangentes.

Diferente das concepções políticas de justiça, as outras concepções morais possuem um maior alcance de aplicação e um leque mais amplo dos objetos que requer. Nas palavras de John Rawls (2011, p. 15):

É abrangente quando inclui concepções sobre o que tem valor na vida humana e ideias de caráter pessoal, bem como ideiais de amizade e de relações familiares e associativas e tudo o mais que deve orientar nossa conduta no limite em nossa vida como um todo. Uma concepção é inteiramente abrangente quando abarca todos os valores e virtudes reconhecidos dentro de um sistema articulado de forma precisa, ao passo que é parcialmente abrangente quando compreende determinados valores e virtudes não políticos, mas de modo algum todos, e quando é articulada de forma menos rígida. Muitas doutrinas religiosas e filosóficas aspiram a ser tanto gerais como abrangentes.

Por outro lado, uma concepção política é uma perspectiva que se sustenta por si mesma e, embora encontre modos de se justificar em uma ou mais doutrinas abrangentes, ela não se deriva destas. Deve ser compreendida como um "módulo" que se encaixa e compatibiliza nas distintas doutrinas abrangentes razoáveis que se manifestam no sistema social por ela regulado e inclusive podendo conquistar apoio das mesmas. A concepção política "tenta elaborar uma concepção razoável somente para a

\footnotetext{
${ }^{12}$ Como destaca Igor Ascarelli Castro de Andrade (2008, p. 180), Rawls “[...] considerava em Uma teoria da justiça que a estabilidade de uma sociedade bem-ordenada dependia de todos os cidadãos, ou, pelo menos, de a maioria deles, terem como base uma teoria filosófica abrangente bem definida, que era a teoria da justiça como eqüidade. No entanto, também o utilitarismo pressupunha, e ainda pressupõe, que a estabilidade de sua sociedade bem-ordenada depende de todos os cidadãos aceitarem uma concepção ou doutrina abrangente [comprehensive doctrine or conception], que, neste caso, é o princípio da utilidade social. As duas teorias aparentemente convergiam quanto a uma doutrina abrangente aceita por todos como condição de estabilidade.". Neste sentido, a obra Liberalismo Político teve total relevância na reformulação de uma teoria propriamente política e aceitável, mesmo em uma sociedade tão plural. Cf. ANDRADE, Igor Ascarelli Castro de. O Liberalismo Político de Rawls ante a Teoria Discursiva de Habermas: o consenso por sobreposição e a razão pública na fundamentação liberal do Estado Democrático de Direito. Rev. Fac. Direito, UFMG, Belo Horizonte, n. 53, p. 177-202, jul./dez. 2008. Disponível em: <http://www.direito.ufmg.br/revista/index.php/revista/article/view/82/78> Acesso em: 06 jan. 2015.
} 
estrutura básica e tanto quanto possível não envolve nenhum compromisso mais profundo com qualquer outra doutrina" (RAWLS, 2011, p. 15).

Neste sentido, o libertarianismo nozickiano parece se caracterizar enquanto uma doutrina abrangente, pois sua amplitude de aplicação se relaciona com os mais variados objetos e sua perspectiva, como do direito natural de não interferência, demonstra tal rigidez que supera os termos da razoabilidade para a definição da estrutura básica da sociedade, embora mantenha a racionalidade própria do individualismo.

Entretanto, enquanto doutrina abrangente, não há que se desconsiderar por completo a sua contribuição, haja vista que seus componentes conceituais, como a liberdade negativa e os princípios de compensação e epistêmico, podem contribuir à constituição de uma concepção política razoável de justiça em prol da autodeterminação do indivíduo. Diante desta consideração, seria necessário entender em que sentido a razoabilidade, própria de uma concepção política de justiça, se distancia da racionalidade contida no pensamento de Robert Nozick.

\section{A racionalidade e a ausência da razoabilidade}

A teoria desenvolvida por Nozick se respalda numa concepção moral e política própria de sociedade centrada na valorização última do indivíduo expressa pela tutela de sua liberdade negativa, ou seja, na garantia de não interferência em que o sujeito seja guiado por sua própria vontade e o direito do outro indivíduo seja restrição moral indireta, dado que é o limite da liberdade de agir. O Estado Mínimo, por sua vez, tem como função a defesa dos indivíduos por meio da manutenção da segurança, em decorrência de uma legitimidade moral e constituída por um monopólio de fato e não de direito.

Identificados estes aspectos basilares e em alguns termos absolutos, torna-se necessário compreender em que medida a perspectiva nozickiana poderia gozar de reconhecimento perante uma sociedade marcada pelo pluralismo de concepções de vida boa, sejam filosóficas, morais e religiosas. Embora Nozick não se preocupasse com a intencionalidade e a possibilidade de convencimento, tendo em vista que a própria tentativa de convencimento poderia representar um ato coercitivo contra a vontade individual, este exercício permitiria entender os possíveis obstáculos a sua implementação, inclusive afetando diretamente as certezas guiadas pela mão invisível.

De imediato qualquer individualista poderia alegar a impossibilidade total de avaliar o pensamento libertário como razoável ou racional, pois a razoabilidade, em termos rawlsianos, é elemento da concepção de sociedade enquanto sistema equitativo de cooperação. (RAWLS, 2011, p. 58-59). Porém, já foi suscitado anteriormente que a perspectiva cooperativa, mesmo que mínima, também pode ser encontrada como plano de fundo da teoria de Robert Nozick, porém não comprometida com uma abordagem em termos 
equitativos. Logo, seria possível a continuidade de tal análise, em benefício da própria teoria e da possibilidade de seu amplo reconhecimento enquanto alternativa de concepção política razoável de justiça.

Para tanto, é essencial resgatar algumas características elementares inerentes à ideia do racional e do razoável. Primeiramente, não há uma relação de dependência, derivação, consequência ou exclusão entre as ideias de racional e razoável, apenas são noções complementares (RAWLS, 2011, p. 61).

\begin{abstract}
Agentes que fossem somente razoáveis não teriam fins próprios que desejassem realizar por meio da cooperação equitativa; e agentes que são somente racionais carecem de um senso de justiça e não conseguem reconhecer a validade independente das demandas de outros (RAWLS, 2011, p. 62).
\end{abstract}

A razão, em termos gerais, é tida como a maneira ou a capacidade de se articular planos e projetos, ordenar finalidades e prioridades e se decidir em consonância a tais procedimentos, sendo realizável por todo agente numa sociedade política, sejam indivíduos razoáveis e racionais ou mesmo instituições e associações dela participantes (RAWLS, 2000a, p. 261). Portanto, o racional é aplicável ao indivíduo, seja único ou unificado (trazendo como referência também a pessoa jurídica), munido da capacidade de julgamento e deliberação, no momento em que almeja atingir fins ou mesmo interesses que são distintivamente seus. Não obstante, não se limita a relação meios-fins, "porque se veem obrigados a avaliar fins últimos de acordo com o significado que têm para o próprio plano de vida como um todo e segundo o modo como esses fins se coadunam e se complementam mutuamente" (RAWLS, 2011, p. 60).

É interessante que, no caso do agente racional, não significa os interesses se voltarão sempre a si, pois nem todo interesse beneficia o próprio indivíduo. Para Rawls (2011, p. 60), faltaria na racionalidade uma parte da "sensibilidade moral" que estimular ao desejo de se empenhar no sistema equitativo cooperativo, esperando que outros, em iguais condições, também venham a aceitar. Porém salientar: "Não estou supondo que o razoável abranja a totalidade da sensibilidade moral, e sim que inclua a parte que tem relação com a ideia de cooperação social equitativa" (RAWLS, 2011, p. 60).

Por sua vez, o razoável é público, de modo que as razões podem ser expostas, compartilhadas e reconhecidas publicamente, inclusive, como base das relações sociais, estruturando um "mundo social público" que possa ser endossado por todos. Porém também não é possível ignorar que sem um mundo social público, o razoável se submeteria tal qual o racional, "ainda que sempre obrigue in foro interno" (RAWLS, 2011, p. 64). O razoável parte da ideia de reciprocidade, supondo que todos poderão endossar tais termos, encontrando-se entre a imparcialidade (que tem um 
conteúdo altruísta e o bem geral integra sua motivação) e a possibilidade de benefício mútuo. Porém não se significa que agentes razoáveis passem a agir encorajadas pelo bem comum, mas como um fim em si mesmo para um mundo social em que possam cooperar de modo que também possam ser aceitas (RAWLS, 2011, p. 59).

Logicamente, Rawls não pretende afirmar que a racionalidade conduziria constituição de agentes que desconsideram a lealdade e outros vínculos especiais, ao contrário, agentes racionais poderiam considerar tais vínculos para o reconhecimento das pretensões dos outros, porém não poderiam reconhecer a validade de tais pretensões independentemente de tais vínculos especiais. (RAWLS, 2011, p. 62).

Frente a estas considerações, nitidamente a teoria moral e política de Nozick evidencia uma racionalidade particular, pois todos os institutos e conceitos se estabelecem de forma concatenada e absoluta em prol da tutela do direito natural, ilidindo-se o sistema marcado pela coerção e violação dos direitos individuais, especialmente, com a defesa de um Estado Mínimo moralmente legítimo e detentor do monopólio de fato, não de direito, da força. Todavia, a racionalidade pode ser identificada pela articulação desenvolvida, selecionando e priorizando, para a efetivação de determinados interesses, lembrando-se que mesmo as instituições religiosas e suas doutrinas expressam laços de racionalidade particularizados.

Porém, a perspectiva do razoável se demonstra bem mais restrita em sua teoria, visto que o direito de não interferência (não coerção) é traduzido em linhas absolutas, excluindo de imediato a possibilidade de uma reciprocidade $^{13}$ frente a diversidade de concepções de vida boa, seja de cunho filosófico, religioso ou não. A simples defesa da existência de uma situação de justiça em que toda perspectiva individual seja frustrada pela ausência de acesso às oportunidades no seio social já seria motivo de não endosso por boa parte dos agentes sociais, exceto os que realmente defendem a liberdade (negativa) individual inabalável. A própria minimização do público indicaria um esvaziamento da razoabilidade, embora esta esteja presente em fundamentos como (i) a defesa do indivíduo como um fim em si mesmo e não meio a ser sacrificado em prol de determinados interesses e (ii) o senso de compensação (talvez de responsabilidade) na tutela dos independentes na aplicação de procedimentos confiáveis pelo Estado Mínimo. Embora dispense o

\footnotetext{
${ }^{13}$ O libertarianismo, que garantiria a manutenção da diversidade pela tutela da não coerção, em grande medida, propõe uma ordem política e social como mero modus vivendi, ainda que os indivíduos não estejam impedidos de acordar voluntariamente por relações que considerem importantes e seja marcada por uma maior carga motivacional. Porém, tais relações expressamente anuidade só seriam viabilizadas quando compartilhado valores uniformemente. As demais divergências resultariam conflitos que em última instância seriam resolvidos por um Estado factualmente dominante, porém sem garantir que realmente não estaria sendo o mesmo repreensor como o Estado monopolista de direito, motivo das críticas do pensamento de Nozick.
} 
argumento e a preocupação com a intencionalidade, certamente o predomínio do racional e a ausência da razoabilidade colocam em dúvida se o direcionamento teórico se daria totalmente como deduzida pela explicação da mão invisível, pois a lógica de mercado não é a regra definidora das relações sociais e nem mesmo termo comum das diversas visões de vida.

\section{Conclusão}

Notadamente, o pensamento de Robert Nozick tem inúmeras contribuições à teoria moral e política, embora pouco divulgado. Em síntese, pode-se destacar uma teoria fundada em direitos e não em objetivos, que pretende desconsiderar a intencionalidade na conformação da teoria política e encontrar um argumento consistente acerca da necessidade ou não do Estado existir. Mesmo que o Estado Mínimo de Nozick abandone a concepção tradicional, de influência weberiana, é evidenciada uma dinâmica política centrada no indivíduo. Os direitos em sua teoria, como destacado por Gargarella, são negativos, consistindo em restrições laterais aos outros sujeitos e de caráter exaustivo.

Seu pensamento é caracterizado pela primazia da autodeterminação e considera inadmissível o sacrifício dos direitos individuais em prol da coletividade ou do outro, pois instituições não se sacrificam e sim indivíduos, motivo pelo qual sustenta de modo absoluto a não interferência. Diferente de Rawls que enfatiza um conceito de liberdade positiva, para Nozick não há direitos positivos e a própria liberdade, enquanto direito natural, é tratada em seu sentido negativo. Porém, ao definir a atuação de seu Estado Mínimo, inclusive na proteção dos independentes, Nozick enfraquece sua teoria com um suposto direito positivo de proteção identificado indiretamente, sob o argumento da efetividade da tutela do serviço de proteção e como medida decorrente do princípio da compensação.

O conceito de sociedade política em Nozick é mais ampla e aberta, não se tratando de cidadãos, mas de indivíduos guiados por suas vontades, trocas voluntárias e alicerçado no direito de propriedade, que de algum modo acaba por ser definidor de uma estrutura básica de sociedade e de condições qualificadoras das situações e circunstâncias como reprováveis ou não moralmente.

$\mathrm{Na}$ interpretação de Kymlicka, seria admissível considerar que o pensamento político de Nozick não é instituído em uma teoria da liberdade, pois a autopropriedade ou posse de si mesmo é independente e não derivado desta. Ainda assim, Nozick reconhece no ser humano um valor intrínseco, sendo o sujeito responsável pelos acordos e pactos celebrados, respeitandose os limites dos direitos naturais.

Em termos políticos fundamentados em conceitos rawlsianos, o projeto de Nozick se caracteriza enquanto uma doutrina abrangente e não 
propriamente uma concepção política compartilhável de justiça, ainda que racional, pois se baseia em verdades absolutas (como o direito natural de não interferência) e se demonstra restrita quanto ao potencial de razoabilidade, embora possa ser considerado de algum modo pela sociedade em termos plurais.

\section{Referências bibliográficas}

ANDRADE, Igor Ascarelli Castro de. O Liberalismo Político de Rawls ante a Teoria Discursiva de Habermas: o consenso por sobreposição e a razão pública na fundamentação liberal do Estado Democrático de Direito. Rev. Fac. Direito, UFMG, Belo Horizonte, n. 53, p. 177-202, jul./dez. 2008. Disponível em: <http://www.direito.ufmg.br/revista/index.php/revista/article/view/82/78> Acesso em: 06 jan. 2015.

BARRETO, André Assi. A defesa do libertarianismo de Robert Nozick. In: XVI Encontro Nacional da ANPOF, 2014, Campos do Jordão. Disponível em:

<www.encontro2014.anpof.org/arquivo/download?ID_ARQUIVO=2848>. Acesso em 22 dez. 2014.

DWORKIN, Ronald. Justice for Hedgehogs. Massachusetts: Harvard University Press, 2011.

GARGARELLA, Roberto. As teorias da justiça depois de Rawls: um breve manual de filosofia política. Trad. Alonso Reis Freire. São Paulo: Martins Fontes, 2008.

KYMLICKA, Will. Filosofia política contemporânea. Trad. Luís Carlos Borges. São Paulo: Martins Fontes, 2006.

MORRESI, Sergio D. Robert Nozick e o liberalismo fora de esquadro. Revista Lua Nova, vol. 55/56, 2002, p. 285-296.

NAGEL, Thomas. Nozick: Libertarianism without Foundations. In: Other Minds. Critical Essays 1969-1994. Oxford University Press, 1995, p. 137 149.

NOZICK, Robert. Anarquia, Estado e Utopia. Trad. Fernando Santos. São Paulo: Martins Fontes, 2011.

RAWLS, John. O Liberalismo Político. Trad. Dinah de Abreu Azevedo. 2. ed. 2. imp. São Paulo: Editora Ática, 2000a. . Justiça e Democracia. Trad. Irene A. Paternot. São Paulo: Martins Fontes, 2000b.

Fontes, 2011. O Liberalismo Político. Trad. Álvaro de Vita. São Paulo: Martins . Teoría de la justicia. trad. de María Dolores González. México: Fondo de Cultura Económica, 1995. . A theory of justice. Ed. Rev. Massachusetts: Harvard University Press, 1999. 
SILVEIRA, Denis Coutinho. A Justificação por Consenso Sobreposto em John Rawls. Philósophos. 12 (1): 11-37, jan./jun. 2007. Disponível em: <http://www.revistas.ufg.br/index.php/philosophos/article/view/4764> Acesso em: 19 jan. 2014. 